\section{EL VIAJE A MARTE DE MODESTO BROCOS}

\author{
Agustín Jaureguízar \\ Doctor Ingeniero de Caminos \\ Periodista
}

\section{MODESTO BROCOS' TRIP TO MARS}

\begin{abstract}
Modesto Brocos (1852-1936) was a remarkable painter from Santiago de Compostela who emigrated at an early age to Brazil, where he lived, held in high regard, up to his death. In 1930 he published in Valencia, in Castilian, his only work of fiction, an unobtainable Voyage To Mars which is a true socialist utopia. That whole world is established as a single global state, of which he details all that goes from a Constitution to Municipal Ordinances, through the administration of justice, education, health and Women's Rights, with only one race and one language, and as peculiar a institution as the Agricultural Army or the Humanitarian Sisters.
\end{abstract}

KEY WORDS: Modesto Brocos; Benito Feijoo; Voyage to Mars; Global state; Socialist utopia; Alien society; Unity of race; Women's Rights; Agricultural Army; Humanitarias Sisters.

Como he detallado en otros artículos, hubo españoles que viajaron en sueños a la luna desde el siglo XVI, antes del mismísimo Kepler, como fue el caso del clérigo Juan Maldonado en 1532, del Gran Piscator de Salamanca, Diego Torres de Villarroel en 1724 y del conocido como el abate Marchena en 1787. En 1804 el también clérigo Antonio Marqués y Espejo ya lo hizo en un navío aéreo en Viage de un filósofo a Selenópolis, que personaliza en él lo que antes hiciera un viajero francés.

Hubo luego quienes marcharon a la luna en globo en el siglo XIX, como Joaquín del Castillo y Mayone en su Viage somniaéreo, o Aureliano de Colmenares, conde Polentinos, en Selenia. Y, finalmente, algunos más se encaminaron a otros astros, como Antonio de San Martín en su Viaje a Júpiter, o Tirso Aguimana de Veca, seudónimo de Agustín María Acevedo, a Saturno en la larga novela Una temporada en el más bello de los planetas.
RESUMEN: Modesto Brocos (1852-1936) fue un notable pintor compostelano que emigró joven a Brasil y alli vivió respetado hasta su muerte. En 1930 publicó en Valencia, en castellano, su única obra de ficción, un inencontrable Viaje a Marte que es una auténtica utopía socialista. Todo ese mundo está constituido en un solo estado planetario, del que detalla cuanto va de una Constitución a unas Ordenanzas Municipales, pasando por la administración de justicia, la educación, la sanidad y la igualdad de derechos entre los sexos, con una raza única y una lengua única, contando con instituciones tan peculiares como el Ejercito Agrícola o las Hermanas Humanitarias.

PALABRAS CLAVE: Modesto Brocos; Benito Feijoo; Viaje a Marte; Estado planetario; Utopía socialista; Sociedad extraterrestre; Unidad de raza; Igualdad de derechos entre sexos; Ejército Agricola; Hermanas Humanitarias.

Pero el primer viaje a Marte no llegó hasta bien entrado el siglo XX y correspondió, ya en avión, al compostelano Modesto Brocos', escrito a la par que otro de Benigno Bejarano, que voló en un vehículo interplanetarioº ${ }^{2}$ del que se ocupó extensamente Julia María Labrador Ben en el número anterior de esta misma revista ${ }^{3}$. Aunque de muy diferente factura, ambos fueron obra de autores comprometidos y ambos describen a su manera una sociedad marciana con una civilización más adelantada que la nuestra en un millón de años y un desarrollo moral todavía más avanzado, como suele suceder en esta estirpe de narraciones.

No puede dejar de señalarse que, aún siendo ambos muy de izquierdas, Brocos vivió cómodamente en Brasil, sin sufrir el menor problema, para escribió una novela de socialismo utópico, cercano al anarquismo y a la literatura de combate. Bejarano, en cambio, escribió una novela casi de humor para una revista burguesa, pero conoció la cárcel, se 
batió en la guerra civil, hubo de exilarse y fue brutamente muerto en un campo de extermino nazi. La vida presenta a veces estas paradojas.

Cabe preguntarse por qué nuestro autor escogió precisamente Marte para situar la acción de su novela. Seguramente porque ya por entonces se hablaba del Planeta Rojo como el más parecido a la Tierra -Brocos demuestra que ha leído algo sobre él porque hace suya la teoría de los canales marcianos- y susceptible de haber conocido una antigua civilización. Quizá también por la notoriedad y el éxito alcanzados por la película soviética Aelita, una utopía socialista en Marte rodada en 1924 por Yakov Protazanov sobre la novela del mismo título de Alexis Tolstoi.

El Viaje a Marte de Brocos no oculta ni por un momento sus propósitos. La tesis primera de cualquier utopista es que la utopía de hoy será la realidad del mañana y él la expone con claras palabras ya en el prólogo:

Es bien posible que tú lo leas como si fuera un romance, tus hijos también lo leerán como un pasatiempo, pero tus nietos tengo la certeza de que lo leerán con más atención que tú [...] Será muy posible que en el fin de tu vida veas realizadas algunas de las utopias que presento en este libro.

Y en la dedicatoria va a expresarse con mayor decisión aún:

Hoy la forma republicana es el gobierno de la mitad de Europa y tiende a serlo del mundo todo [...] Los credos socialistas son considerados en muchas naciones partidos legales y el mundo camina a pasos de gigante hacia la consecución de mejorar lo existente.

La utopía es una literatura peculiar de anticipación o de mundos paralelos que, cómo escribe Neussüs ${ }^{4}$, supone ante todo la repulsa de unos contravalores, autoritarismo, miseria, ignorancia, injusticia, y la afirmación de una vida que alcanza una plenitud de felicidad, de bondad, de razón, en consecuencia, de igualdad. En toda utopía subyace el deseo de un orden de vida auténtico y justo que se expresa, según las distintas narraciones, no por el análisis del orden existente e injusto, sino por una idea óptima de futuro; de otros mundos, habría que apostillar aquí.
La utopía humanística cristiana se escribió en España desde el siglo XVI, en una serie de narraciones de las que algunas sólo en estos últimos años se están dando a conocer. Pero a partir de finales del XIX se produjeron otras de signo muy distinto, las utopias sociales cuya gran aportación es el esfuerzo por construir una alternativa radical tanto frente al pensamiento conservador como frente a la tradición marxista ortodoxa, dicho en palabras de Horowitz ${ }^{5}$.

Se trata de cuadros de algo que no existe, que es solamente imaginario, cuadros-fantasía, que escribe Modesto Solla ${ }^{6}$, en la línea de Buber, pero una fantasía que no divaga, sino que se centra en torno a algo primordial y originario que tiene que elaborar. $Y$ ese algo es un deseo. La imagen utópica es un cuadro de lo que debe ser, lo que su autor desearía que fuese real. Así, el "debe ser" utópico se contrapone al "ser" real. La utopía, como más o menos dijo Nettau, es el enlace perdido entre el porvenir y el presente, entre los sueños que tenemos y los hombres que somos.

\section{Modesto Brocos}

Isidoro y Modesto Brocos Gómez fueron dos artistas compostelanos, el primero escultor -profesor de modelado de Picasso en A Coruña-, el segundo pintor y grabador, que desarrolló buena parte de su actividad fuera de España. El Ayuntamiento de su ciudad lo ha reconocido dando su nombre a una calle.

Modesto nació en Santiago de Compostela el 9 de febrero de 1852 en el seno de una familia modesta dedicada desde antiguo al oficio del arte. Realizó sus primeros estudios en la Real Sociedad Económica de Amigos del País, el lugar de Santiago en que podía recibir una educación artística de calidad. En 1871, con sólo diecinueve años de edad, emigró a Buenos Aires; allí trabajó como grabador en madera y cobre. Después fue a Río de Janeiro, donde ingresó en la Academia Imperial de Bellas Artes y empezó a publicar en el periódico $O$ Mequetrefe.

En 1877 regresó a Europa y por dos años cursó estudios en la Escuela Superior de Bellas Artes de París, formación que prosiguió en Madrid en la Academia de Bellas Artes de San Fernando. De esos años, 1879-1881, datan sus colaboraciones en La llustración Gallega y Asturiana de 


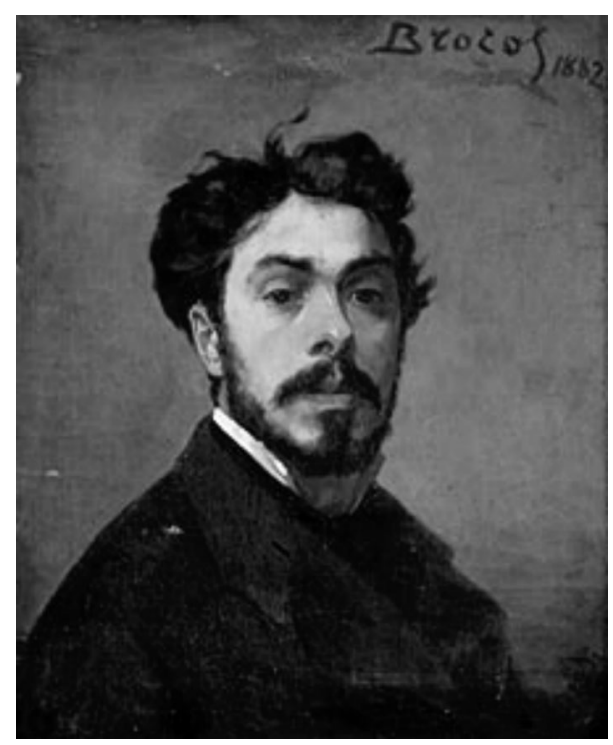

Manuel Murguía, que prestaba gran atención a los temas artísticos y culturales.

Regresó a Francia y enseguida marchó a Italia, donde por cuatro años frecuentó la Academia Gigi y la del Círculo Internacional, gracias a una bolsa de estudios que le concedió la Diputación de A Coruña por su cuadro Rebeca dando de beber a Eliezer: siempre dijo que le gustaba más Paris que Roma. Tras retornar a Galicia y obtener cátedra por oposición en la Sociedad en que había cursado sus primeros estudios, en 1890 estableció definitivamente su residencia en Brasil, donde formó parte del claustro de profesores de la Escuela Nacional de Bellas Artes.

Fue un pintor ecléctico que lo mismo cultivó el retrato que el paisaje, las escenas marineras y de costumbres que la pintura social o religiosa, "dibujante excepcional y retratista primoroso, capaz de penetrar en la sicología de sus personajes y darnos de ellos no la mera imagen exterior, sino su carácter", que escribe Francisco Pablo Holgado en Plástica gallega ${ }^{7}$. Obtuvo varios premios, como el de Honor del Gobierno de Brasil por La rendición de Caín, y uno de sus cuadros, La tradición del apóstol Santiago, puede verse en la sacristía de la catedral compostelana, lo mismo que la obra maestra Las tres edades en la Diputación de A Coruña. Brasileño adoptivo, decoró la Biblioteca Nacional de este país y otros edificios públicos. Falleció en Río el

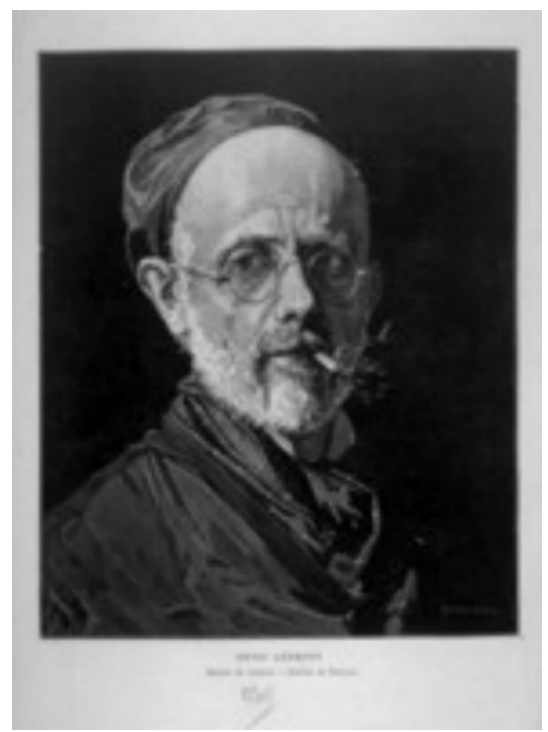

28 de noviembre de 1936, a los ochenta y cuatro años de edad.

Río y São Paulo han conocido grandes exposiciones de su obra y en 2004, en Santiago, pudieron contemplarse algunos de sus cuadros en la exposición "Pintores composteláns".

Escribió algún libro de arte, tal la Retórica de los pintores y otros en portugués, mas, como escritor de ficción, fue un auténtico auctor unius libri, sólo dio a la imprenta este hoy inencontrable Viaje a Marte en 1930, escrito dos años antes, a los 76 de edad, cercana a la del sepulcro que él mismo dijo. Dijo asimismo que en su juventud había sido autoritario y soñaba con imponer sus ideas por la fuerza a quienes no las compartiesen, para en su madurez preguntarse si no sería preferible conservar la organización del mundo tal cual era, contentándose con corregir sus defectos y dignificar sus instituciones: tal es la decidida intención de su obra.

\section{Viaje a Marte}

Se trata de una novela ambiciosa, una utopía plenamente llevada a la práctica de la que se describe detalladamente 
todo cuanto va de una Constitución a unas Ordenanzas Municipales, pasando por los usos y costumbres de un pueblo entero, que ya no habita el aislado locus amoenus de las utopías clásicas, sino todo un planeta: si no figura en las antologías de utopías socialistas se debe a su desconocimiento.

Hay que decir también que es una obra del más completo estatismo narrativo en aras del adoctrinamiento políticoreligioso. Sigue en buena medida la forma -plena de diálogos y, aún más, de monólogos interminables- del Telémaco de Fenelon, con un Feijóo que juega el rol de Mentor y un Brocos que desempeña el papel de Telémaco.

Sólo he encontrado una referencia a ella en la revista Estudios migratorios ${ }^{8}$ :

Ya en su vejez, Modesto Brocos se reafirmó en sus convicciones sobre el blanqueamiento como condición de progreso en su creencia en la regeneración de las razas a partir del "bueno y controlado mestizaje" y publicó sus ideas en Viaje a Marte, obra que se podría incluir en el género utópico y en la que sitúa la civilización ideal en el planeta marciano. En ella Brocos describe la evolución histórica de la sociedad de Marte, paradigma ideal de la humana.

Y reproduce a su vez dos párrafos de la novela:

Siguiendo, pues, la humanidad marciana en esa aspiración fatal y constante, después de alcanzar un perfeccionamiento nunca hasta entonces imaginado, aquella humanidad no estaba satisfecha, pensaron que aún faltaba una gran reforma a introducir en el planeta, cual era la de unificar las razas fundiéndolas en una sola para que la desigualdad desapareciera al menos en el aspecto exterior de las gentes. Ya se había conseguido mucho en tiempos anteriores mejorando las razas separadamente, de modo que la raza blanca con la amarilla fue fácil el mestizaje. No aconteció lo mismo con la raza negra, que si bien se había tenido anteriormente cuidado de seleccionar, ofrecía dificultades por el color. De esta tan ardua tarea se encomendó de llevar a feliz término al Ejército Agrícola y a las Hermanas Humanitarias.

Introdújose entre aquellas razas al ejército y a las Hermanas como principal elemento durante una generación, juntándose a éstos los voluntarios y voluntarias que se ofreciesen a ir con el mismo laudable fin, y pasado ese tiempo se dejaban abandonadas a sí mismas durante dos generaciones. En este espacio de tiempo las razas inferiores se iban perfeccionando entre si, hasta quedar confundida la primera inoculación. Luego volvíase a enviar los soldados y las Hermanas Humanitarias para renovar la sangre de aquellas razas, y por dos generaciones se las dejaba aisladas. $Y$ continuando periódicamente estas medidas la piel se fue aclarando hasta llegar por último a quedar del color de los otros habitantes. Este trabajo fue largo, cerca de mil años tardó en realizarse, pero la unificación fue un hecho real, y hoy la raza que en algunas comarcas quedó sin mezcla no le es superior a esta conseguida artificialmente.

Empiezo por el principio. Brocos, sin ocultar su condición ni su nombre, narra en primera persona una historia que arranca, a modo de viaje iniciático ${ }^{9}$, con su llegada a Marte en una nave claramente irreal de la que es el único pasajero que desciende. Las utopias empezaron situándose en remotas "islas felices" pero, a medida que avanzaba la exploración de la Tierra, se fueron llevando a los lugares más inaccesibles, que finalmente fueron otros mundos.

Da gracias a Dios por haber logrado el sueño de su vida, que era alcanzar ese mundo para conocer los hábitos sociales y políticos de sus pobladores, y dirige la vista desde lo alto al paisaje que se ofrece ante sus ojos, que le recuerda los campos de Pontevedra.

Baja del monte, se echa a andar y se tropieza con sus primeros marcianos, gentes amables que nunca han visto a un viajero de otro universo, hasta que se le acerca el que fuera gallego como él en su anterior encarnación en la Tierra, fray Benito Jerónimo Feijóo, quien le invita a alojarse en su casa.

Y ésta es toda la acción de la novela, ya que el resto está compuesto, sin tregua ni pausa, por las visitas que realiza y los discursos elucidatorios del ex fraile de san Benito, "el primer socialista español"10, en un recurso común en los viajes a otros mundos, aquí un tanto exagerado.

Los principios de la vida en Marte se enuncian en la propia cubierta del libro y proclaman la unidad política del planeta, su unidad de lengua, raza y religión, la igualdad absoluta entre hombres y mujeres, la inexistencia de la propiedad privada del suelo, la administración de justicia, 
la educación universal, el funcionamiento del ejército y de su peculiares conventos, etc., todo ello por derecho consuetudinario, pues no existen leyes escritas: los marcianos viven un socialismo ideal, nemine discrepante, en la armonía perfecta para la que son educados.

El contrafactual de partida de toda utopía -de toda eutopía si queramos excluir las utopías negativas o distopías- radica en que el hombre es naturalmente bueno y son la educación que recibe y la sociedad en que se integra las que lo hacen insolidario e infeliz. La insolidaridad e infelicidad se inician con el establecimiento de la propiedad privada y siguen con la creación de la autoridad y las leyes impuestas, esto es, con el sometimiento del individuo al poder de otros individuos sobre él.

Al entrar en el detalle veremos que se citan multitud de leyes, normas y disposiciones vigentes, empleándose expresiones como "tocante a este particular, las leyes son explícitas", "sufren los requisitos más rigurosos de la ley" y otras de la misma laya: es uno de los reparos que por contradicción se pueden poner al libro. Otro sería que describe una civilización un millón de años más adelantada que la de la Tierra pero que se asemeja a la terrestre de siglos atrás, una sociedad agrícola en la que una región cifra su riqueza en función de las subsistencias de que dispone, medidas en productos del campo: éstos son sus bienes y en su recolección se afana la mitad de su población masculina.

No considera, por ejemplo, la existencia de alimentos elaborados ni de apenas otros bienes de consumo; los campesinos llevan los productos del campo a los mercados de las ciudades en carros tirados por animales, no aparecen

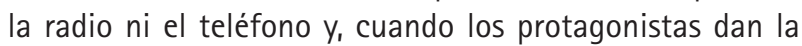
vuelta al planeta, los barcos transcontinentales son grandes veleros y en el aéreo que toman se sientan al aire libre, buscando el lado en que no da el sol.

Como todo utopista que se precie, describe una ciudad con un urbanismo racionalmente geométrico, de calles rectas y perpendiculares que conforman un a modo de tablero de ajedrez cortado por dos anchas avenidas diagonales por donde discurre el tráfico rodado de auto-coches y autoómnibus, movidos por la energía del hidrógeno que se extrae del agua de los océanos, una valiosa anticipación: el carbón de las minas se agotó en quince siglos y después

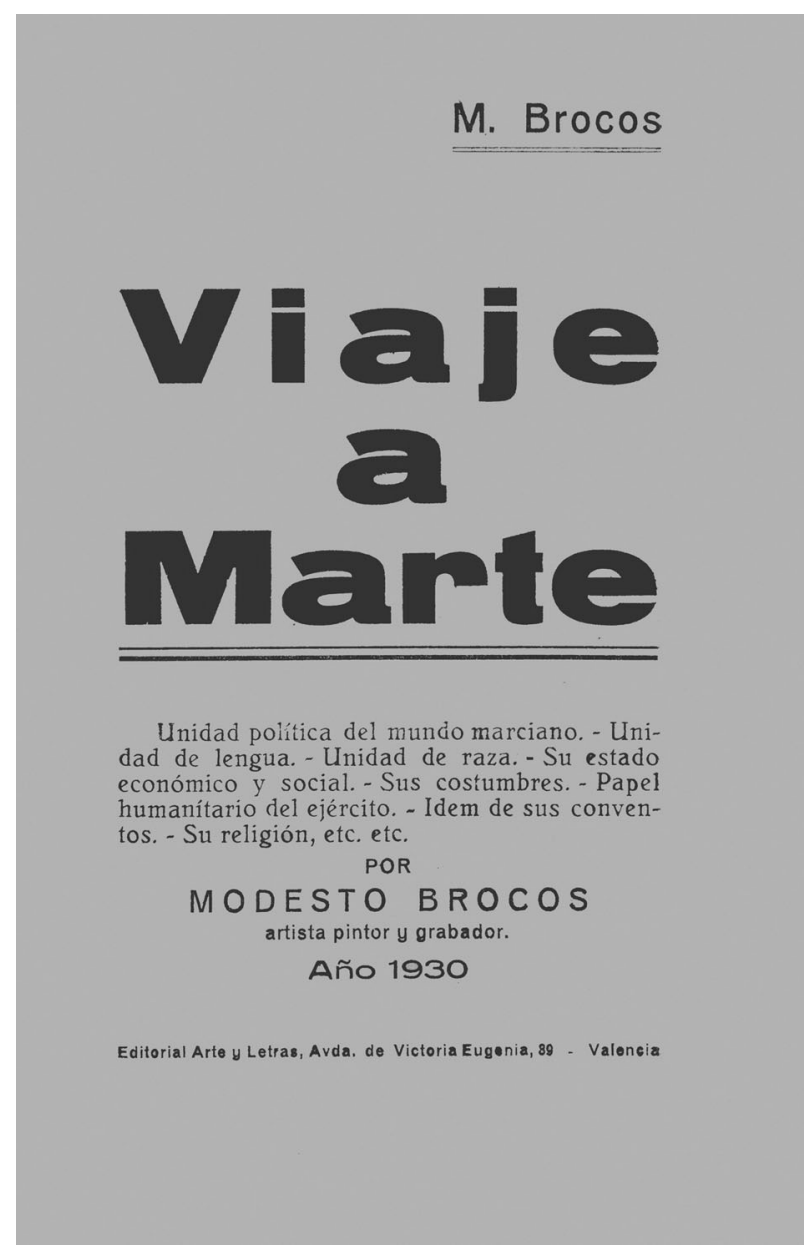

se agotaron también los óleos fósiles que lo sustituyeron como combustible.

Ya Hipódamo de Mileto" construía según criterios geométricos de simetría, de inspiración pitagórica, que también informan su doctrina social. Desde entonces, las referencias a la simetría en las ciudades utópicas se repiten en obras sucesivas, que entienden que, en la construcción geométrica, la razón domina el desorden de la materia.

Dado cuanto explica de los municipios marcianos -vuelvo a Brocos-, se puede estimar que habría en Marte algunos cientos de miles de ellos, de cinco o seis mil habitantes cada uno, repartidos entre la ciudad y las cuatro o cinco aldeas que la circundan. Esta estimación, de la que el autor ni se preocupa, da pie a suponer que las calles de las pequeñas urbes serian veinte o veinticinco en cada dirección, 
conformando manzanas de cuatro casas unidas por sus vértices, cada una con su jardín, más unos cuantos edificios públicos ubicados en las plazas que se crean en las intersecciones de las calles con las avenidas diagonales.

Siguiendo su camino hallan a unos soldados que sólo se parecen a los terrestres en el uniforme. Hace un millón de años, cuando Marte estaba como lo está ahora la Tierra, se realizaron muchos descubrimientos, pero eran tiempos bárbaros en que las naciones se hacian la guerra unas a otras, hasta que -exhaustas- acordaron resolver sus diferencias por medios pacíficos. Dedicaron entonces sus ejércitos a fines sociales, el primero la agricultura, que es la principal industria de Marte.

El ejército, al que todos los hombres prestan tres años de servicio, ayuda a los campesinos que lo precisan, rotura tierras sin cultivar, construye represas y canales de riego y al autor, como a los de su tiempo, le falta la sensibilidad necesaria para impedir que exterminen a los animales y plantas no productivos. El ejército, en definitiva, garantiza la producción de alimentos: Brocos parte del supuesto de que una sociedad feliz ha de basarse en unos estómagos satisfechos.

El otro supuesto que hay que satisfacer es la sexualidad. Brocos y Feijóo se cruzan con dos monjas de la Hermandad Humanitaria, mujeres sumamente respetables y respetadas, que no son como las egoístas religiosas de la Tierra, que dicen que se entregan a los demás pero no lo hacen: ellas se entregan verdaderamente a los hombres por dinero, destinando lo ganado a obras benéficas. En los conventos marcianos no se reza ni se celebran funciones litúrgicas, las hermanas cultivan la música, la danza, el dibujo y las artes escénicas, en las que llegan a ser verdaderas maestras, de modo que las funciones que celebran son musicales o teatrales.

El escritor dedica un largo capítulo a presentar hasta en sus menores detalles el funcionamiento de estos conventos, en cuya exposición se complace. Existe uno por ciudad, con cincuenta hermanas disponibles de 2 de la tarde a 10 de la noche, que esperan en una gran sala a que los clientes las elijan: luego se comportan con ellos como esposas cariñosas ${ }^{12}$.

Existe una Dirección General de Conventos que se ocupa de destinar hermanas de donde sobran a donde faltan y regula su organización. Los usuarios abonan como espórtula la cuarta parte de su jornal de un día y hay conventos en que se admiten propinas o regalos y otros en que no, conventos en que las hermanas pueden visitar en sus días libres a los amigos que han hecho y otros en que no, pero en todos se exige a los usuarios la presentación de un certificado médico de salud.

Se dice en la exposición general que, llegada cierta edad, las mujeres que ni cursen estudios superiores ni se casen, han de ingresar en las Humanitarias, aunque en el detalle se dice que las monjas se eligen prefiriendo, por este orden, a las mujeres histéricas, las de temperamento ardiente y las voluntariosas. Además no profesan de por vida, sino que hacen votos temporales.

A diferencia de cuanto con frecuencia sucede en la Tierra, la castidad no se considera una virtud en Marte, sino una actitud antinatural que sólo practican los viciosos y los enfermos. Los muchachos y las muchachas mantienen ya desde los internados relaciones sexuales a partir de la edad núbil, para llegar al matrimonio escogiendo lo que más les agrada.

Los enlaces se extienden por un período de siete años renovables, siendo el cabeza de familia un día él y otro ella. Durante este tiempo los esposos se guardan fidelidad absoluta, mas, cuando el matrimonio se extingue, suelen seguir viviendo juntos como amigos, permitiéndose otras relaciones $\sin$ consecuencias.

Con sus estómagos y su sexualidad satisfechos, se le escapa al autor decir que los marcianos son sobrios y se complacen principalmente en los placeres espirituales.

Y, sentados los precedentes, vuelvo al "blanqueamiento". Cuando el anfitrión hace notar a su huésped la unidad de raza existente, le explica que, superados los tiempos bárbaros, los soldados y las monjas, originariamente de raza blanca, se aparearon con mujeres y hombres de otras razas, dando lugar a mestizos, y asi lo repitieron cada tres generaciones a lo largo de mil años.

Ya en el tiempo presente, cada municipio elige periódicamente al varón más perfecto de entre los suyos, el cual, durante tres años, puede cohabitar un mínimo de quince días con las mujeres que escoja, siempre que ellas consien- 
$\tan$-que libres de prejuicios suelen hacerlo-, o que ellas se lo pidan y se pongan de acuerdo, sin que su embarazo suponga la menor discriminación para la mujer o su futuro hijo, sino al contrario. En el momento de la acción la disposición está vigente en varios territorios para mejor contribuir a la belleza de la raza.

Al final de las guerras apareció una enfermedad curiosamente parecida al sida, que el autor atribuye a la profanación sexual de cadáveres o a la relación con un nuevo pueblo, hasta entonces intocado. Todos sus portadores fueron esterilizados, sólo se les permitió mantener relaciones con otros esterilizados y sus hijos, si los hubieran tenido antes de descubrirse su enfermedad, fueron igualmente esterilizados, lo mismo que sus nietos, si llegó a haberlos. $Y$ de igual manera se procedió con todas las demás enfermedades infecciosas o hereditarias, de forma que mejoró notablemente la salud del planeta.

Como no podía ser menos en la época, lejos de abusos posteriores como los del nazismo, la eugenesia es radical. Nos enteramos primero de que existe en cada municipio una piscina donde se ahoga a los niños que nacen con algún defecto. Luego que, como la población crece en proporción geométrica mientras que los alimentos lo hacen sólo en proporción aritmética, se limita la demografía escogiendo a las mujeres más sanas y hermosas para procrear, esterilizando a las demás. Ni qué decir tiene que se practica un análisis de sangre a los candidatos al matrimonio y se excluye a quienes sean portadores de la menor tara hereditaria.

Esto deberia dar lugar a una minoría de matrimonios con muchos hijos y una mayoría con ninguno, pero, como al autor no le importa a veces lo que ha dicho en un capitulo a la hora de escribir el siguiente, cuando se ocupa de la educación de los pequeños y de la sociedad marciana en general, la trata como si estuviera toda compuesta por matrimonios con dos o tres hijos.

Así se ha conseguido que haya una raza única y perfecta en Marte, que es lo que le gustaría al autor que hubiera en la Tierra ${ }^{13}$, lo mismo que hay una sola lengua y un solo Estado planetario. Cuando se superaron los tiempos bárbaros, las bases sobre las que se estableció su civilización y que son los principios que rigen su vida fueron tres:
Uno, la absoluta libertad de pensamiento que se hace posible cuando la razón se sobrepone a la inteligencia, lo que se alcanza por la instrucción.

Dos, la emancipación del suelo con la desaparición de su propiedad privada: los agricultores arriendan sus tierras al municipio y éste recibe una parte de sus cosechas como renta.

Tres, la emancipación de la mujer, que es en todo igual al hombre.

Las rentas pagadas en cosechas permiten a los depósitos municipales equilibrar la oferta y la demanda de los granos y legumbres que llevan los campesinos al mercado, interviniendo cuando los precios suben o bajan más de lo debido.

Y por cuanto respecta a la emancipación de la mujer, ya se ha visto que no es tan completa como el autor sostiene, ya que, por más que pretenda equiparar a soldados y monjas, su concepción del servicio de éstas es terriblemente machista. Su imaginación no es capaz de sobrepasar ciertos límites, aunque quepan en ella determinados valores. Cuando llegan las elecciones, por ejemplo, ocupadas ellas en los negocios domésticos y disponiendo por tanto de menos tiempo para darse a conocer en los públicos, se les reserva un tercio de los cargos electivos: en las comicios con listas nominativas, las papeletas que no contengan al menos un nombre femenino por cada dos masculinos, se consideran votos nulos.

En parecida línea, los días pares del calendario son de los hombres y los impares de las mujeres, de modo que, si un baile se celebra en día par, son los caballeros quienes sacan a bailar a las damas, y a la recíproca en los días impares.

El calendario marciano se establece en base a una semana de nueve días, de los que se descansa el último ${ }^{14}$. Todas las fiestas han de celebrarse en el penúltimo día, de modo que la semana no se interrumpa por "puentes", una idea práctica del autor. La jornada laboral es de seis horas matutinas: a su llegada al planeta ya sorprende al visitante ver que los hombres visten como trabajadores por la mañana y como señores por la tarde.

Volviendo a las elecciones, las municipales se hacen por sufragio universal y directo y las nacionales por votación 
de los representantes de cada municipio, pues los ciudadanos de a pie no conocen a los candidatos. Los elegidos no hacen política, se ocupan sólo de la buena administración de la república.

Todo el planeta es una sola nación que habla una misma lengua, con la particularidad de que el Congreso de los Diputados no tiene una sede fija sino que cada cuatro años peregrina de un municipio a otro entre los que son capitales de provincia, a fin de que ninguno alcance una posición dominante sobre los demás.

Feijóo va explicando a Brocos los diferentes usos y costumbres marcianos. Los jueces se eligen entre los ancianos $y_{\text {, }}$ tras oír a los litigantes, imparten justicia de forma oral e inmediata, sin escritos, abogados ni procuradores. Para los pleitos comerciales e industriales existen jueces especiales nombrados por los gremios. Y, si raros son los juicios civiles, aún lo son más los de causa criminal, en los que el reo no sufre pena de cárcel, sino que es enviado a servir a los soldados en los cuarteles como el mejor medio para su rehabilitación.

La medicina es pública y gratuita, dispensándose los mismos cuidados a todos los enfermos, y los cadáveres se incineran en beneficio de la sanidad pública. La limpieza de las ciudades la realizan los propios vecinos, cada uno de los cuales barre la acera y la mitad de la calle que está frente a su casa, existiendo dos tipos de contendedores para depositar en unos los papeles y trapos y en otro los metales, que se reciclan y reutilizan.

La consecución de este estado de perfección social trajo consigo el aburrimiento y la rutina de los ciudadanos, y la pérdida de sus estímulos y ambiciones dio lugar al estancamiento, si no a la marcha atrás, del progreso. Tras varios ensayos se decidió que, tres veces por siglo, habría cinco años de gobierno a la antigua usanza, uno de dictadura, otro de régimen presidencialista y tres de gobierno parlamentario, lo que fue un excelente antídoto y dio un magnífico resultado.

Existen cuatro clases sociales, apreciadas por este orden: trabajadores agrícolas, trabajadores profesionales -médicos, ingenieros, etc.-, trabajadores industriales -obreros- y comerciantes. Estos son los que pagan más impuestos, a más de no poder gravar sino con un porcentaje limitado sus precios de venta sobre los de compra. Tras un millón de años de la nueva sociedad marciana, nada está peor visto que los intermediarios de los tiempos bárbaros, semejantes a los de la Tierra. Un trabajador industrial, en fin, no puede independizarse sin dar participación en la nueva empresa a sus compañeros, es decir, que no crea una empresa libre sino una a modo de cooperativa.

Una mutualidad universal a la manera de nuestra Seguridad Social -que no había en 1928- paga una pensión a quienes no puedan trabajar por accidente, enfermedad o vejez. En ese planeta, en teoría sin leyes y casi sin Gobierno, se da en la práctica un Estado omnipresente que regule los desequilibrios: para los territoriales, por ejemplo, exime de impuestos a los trabajadores e industrias de las regiones menos favorecidas.

La educación primaria se imparte obligatoria y gratuita desde los siete a los trece años, con los niños en internados, separados de sus padres: el programa de estudios está establecido a escala planetaria y a esas edades ya aprenden los rudimentos de la agricultura. La enseñanza secundaria abarca de los catorce a los diecisiete y la especializada de los dieciocho a los veintiuno, pudiendo prolongarse hasta los veintitrés para estudios avanzados. A partir de los veintiuno los hombres han de prestar tres años de servicio en el ejército agrícola y las mujeres ejercer su profesión, si han estudiado, contraer matrimonio o, en principio, ingresar en la Hermandad de las Humanitarias: las que no estudian, de una $u$ otra manera han de ir a la cama.

Escribe Saiz Cidoncha ${ }^{15}$ que, cuando la proto ciencia ficción española aún seguía contando el hallazgo en la luna de los inevitables Elías y Enoch o explorando planetas en los que grandes altavoces lanzaban a la atmósfera estentóreos padrenuestros para edificación de los alienígenas; que, saliéndonos de nuestra casta piel de toro, incluso cuando los autores de proto ciencia ficción americanos negaban en absoluto que en el futuro existiera vida sexual 0 , al menos, se dejaban en el tintero todo lo a ella referente, Modesto Brocos nos presenta una sociedad en la que se hace el amor con la mayor naturalidad.

La última educación es de pago, con programas de estudio que fija cada municipio: si todos disponen de un convento, bien pueden disponer de una universidad. Para quienes tengan cualidades intelectuales y carezcan de recursos 
económicos, existen dieciséis becas por municipio, obligadamente ocho para chicos y ocho para chicas. Habrá una mayoria de municipios, pensará cualquiera, en que la proporción de inteligencias hombre-mujer sea pareja, pero otros en que no, incluso algunos en que los dieciséis mejores sean todos del mismo sexo, pero el autor es un teórico que no desciende al detalle.

Una vez, y por un momento, Brocos entiende que los marcianos son ateos, lo que refuta enérgicamente Feijóo. Son creyentes de un deísmo a la manera del propuesto por la Ilustración francesa, de Voltaire o de Rousseau. Creen en un autor del universo y de las leyes que lo gobiernan, en el Gran Relojero que puso en marcha el universo $y$, tras darle cuerda, se alejó de los asuntos terrenales, por lo que no le dirigen alabanzas ni súplicas, buscando por su sola cuenta la felicidad hic et nunc.

La religión sirvió en principio para regular los trabajos de los hombres y después sus principios morales. Establecidos éstos, unos los fueron discutiendo y recayeron en la incredulidad, mientras quienes buscaba la felicidad en la fe siguieron siendo infelices. El culto está establecido a la Madre Naturaleza, principalmente al cultivo del suelo. ...inteligencia que nos es superior y que ha ordenado esta gran máquina; pero durante los tiempos en que los marcianos levantaban templos, le dirigian preces y especulaban todo de Él, fueron siempre infelices: reinaba aquí la injusticia, el egoísmo, la crueldad en los hombres, la depravación en las costumbres, en suma: ¡la desgracia! Los hombres dijeron: reconocemos la existencia de un Dios, no nos cabe duda, pero vamos a dejarlo descansar en el paraiso que nos ha prometido y de ahora en adelante tratemos de procurarnos la felicidad aqui sobre el planeta.

En una visita a un museo, se remata la novela, "me acometió un vértigo, perdí el equilibrio y...", y con dos líneas de puntos suspensivos se cierra el libro, cuya lectura merece más de una reflexión. Es literatura de combate que, superado el nivel del pasquín o el folleto, de "la palabra como subversión", que escribió el profesor Gómez Tovar, posee la "ética de la belleza" al tiempo que conserva el obligado sentido social y pretende contribuir al irrenunciable deseo de felicidad e igualdad del género humano.

¿Todo ha sido un sueño? Al final la vida es sueño y la utopía aún lo es más, "el sueño del orden de vida verdadero y justo", que dijo Neussüs.

\section{NOTAS}

Recibido: 10 de junio de 2009

Aceptado: 10 de septiembre de 2009
1 Brocos, Modesto (1930), Viaje a Marte, Valencia, Arte y Letras. Está editado en rústica, consta de 387 páginas y costaba 5 pesetas.

2 Bejarano, Benigno (febrero-octubre 1929), El secreto de un loco: Novela, il. Serra Masana. Barcelona: Lecturas, Revista Literaria (Folletines de "Lecturas"). Existen varias ediciones posteriores en libro con variantes.

3 Labrador Ben, Julia María (septiembre-octubre 2009), "Muerte no accidental de un anarquista español: el periodista y escritor Benigno Bejarano muere en un campo de exterminio", en Arbor, 739, pp. 1063-1071. Sobre esa novela véase especialmente Labrador
Ben, Julia María (2009), "Un héroe loco visita Marte. La novela festiva de Benigno Bejarano, un autor de literatura de combate", en Fidel López Criado (ed.), Héroes, mitos y monstruos. Actas del IX Congreso internacional de literatura española contemporánea (Santiago de Compostela: Andavira, 2009), pp. 119-126.

4 Nessüs, Arnhelm (1971), Utopía, Barcelona, Barral.

5 Horowitz, Irving L. (rec.) (1990), Los anarquistas, Madrid, Alianza.

6 Solla Sanz, Modesto, Utopía y derecho. He tomado algún dato más de esta valiosa tesis, todavía inédita.

7 Pablo Holgado, Francisco, "Juicio crítico. Pintura", en W.AA. (1981), Plástica gallega, Vigo: Caja de Ahorros Municipal, p. 106. 
8 Ferreira Bueno, Fernando y Sousa Jiménez, José (junio 2000), "A redención de Cam. Ilustración da política migratoria brasileira nos inicios da República Velha", en Estudios migratorios, 9, pp. 113-127 (cita en p. 124).

9 El viaje iniciático medieval en España, más fantástico y de mirabilia religiosa que utópico, suponía cruzar la frontera del reino de Granada para contar a la vuelta las cosas extrañas y maravillosas que había en tierra de moros; luego se hizo a la recién descubierta América y enseguida a la luna y otros mundos, para tornar luego a la Tierra del futuro.

10 El primer socialista español, en el sentido en que emplea la palabra el autor, bien pudo ser aquel Manuel Sagrario de Veloy, del Círculo gaditano de Joaquín Abréu, que en 1841 pretendió constituir en Tempull una sociedad igualitaria en una zona yerma y deshabitada, por lo que dirigió a la Diputación Provincial de Cádiz un escrito en el que se leía: "La nueva población podrá adoptar aquellos principios del socialismo que aconse- je la prudencia, por su alta moralidad y conveniencia pública": debió de ser la primera vez que se utilizó este lenguaje. He tomado la cita y algún dato más de Gómez Tovar, Luis (1991), "Las curvas del pensamiento", en Utopias libertarias españolas, siglos XIX-XX. Madrid, Tuero.

11 Hipódamo de Mileto (ca. 475-400) construyó el puerto de El Pireo y la colonia ateniense de Turiori en el tiempo de Pericles. Su amor por la simetría fue tal que le granjeó las pullas de Aristófanes, que en Las aves se burla de él con el nombre de Metan.

12 La regulación de la prostitución como un bien social y la concesión de un status a las prostitutas es tema tratado en la literatura fantástica a partir de Le Pornographe, de Restif de la Bretonne, en 1769, aunque las mujeres del francés siguen siendo dignas prostitutas en la consideración social, mientras que las de Brocos son dignas esposas de la Humanidad. Véase mi artículo (enero-febrero 2006), "El descubrimiento del mundo austral por un hombre volador. El extraordinario hallazgo de Restif de la Bretonne", en Galaxia, 18, pp. 52-58.

13 La primera ucronia que se escribió fue Napoleón apócrifo, de Geoffroy, y la ucronía no es sino la utopía de la Historia. En este libro el emperador consigue en toda la Tierra la unidad de lengua y de derecho, de educación y sanidad, y muere sin ver cumplido un único deseo, la unidad de raza, a la que no llegó por falta de tiempo.

14 La aplicación de este calendario al cómputo terrestre daría lugar a cuarenta semanas al año más cinco días -seis los bisiestos- que no formarian parte de la semana, a fin de que las fiestas se celebraran siempre en fecha fija correspondiente al día anterior al de descanso. Hay mejores calendarios posibles, aunque sospecho que las especulaciones al respecto hubieran casi parecido obscenas al buen Brocos.

15 Saiz Cidoncha, Carlos (1988), La ciencia ficción como fenómeno de comunicación y de cultura de masas. Madrid, Facultad de Ciencias de la Información, Universidad Complutense (tesis doctoral). 